\title{
WAVE TRANSMISSION BY OVERTOPPING
}

\author{
by \\ Ralph H. Cross \\ Charles K. Solliłi
}

\section{DEPARTMENT}

OF

CIVIL

ENGINEERING

SCHOOL OF ENGINEERING

MASSACHUSETTS INSTITUTE OF TECHNOLOGY

Cambridge, Massachisetts 02139 


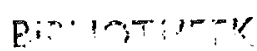

Water: $? ; ;$ i ilim

Póntis i, - L LLLT

Ra1ph M. Parsons Laboratory

For Water Resources and Hydrodynamics

Department of Civil Engineering

Massachusetts Institute of Technology
KAT.

WAVE TRANSMISSION BY OVERTOPPING

by

Ralph H. Cross

Charles K. Sollitt

Technical Note No. 15

December 1970

Prepared Under

Contract No. DACW-72-68-C-0032

Coastal Engineering Research Center

U.S. Army Corps of Engineers

Washington, D.C.

DSR Project 71135 


\section{ABSTRACT}

This report presents a theory for ocean wave transmission past breakwaters by overtopping, based on an evaluation of the energy content of the overtopping water. While several coefficients are subject to further investigation, the data shows that the general form of the equations developed is correct. Comparison with large-scale model tests reinforces this belief, and comparison of an intermediate theoretical result predicting the volume of overtopping water with published data again shows reasonable agreement. An envelope curve for the transmission coefficient, based on all available data, gives a simple tool for preliminary design estimates of the transmission coefficient. 


\section{ACKNOWLEDGEMENTS}

This study of wave transmission past breakwaters was sponsored by the Coastal Engineering Research Center of the U. S. Army Corps of Engineers under Contract No. DACW-72-68-C-0032. Contract administration was provided by the M.I.T. Division of Sponsored Research under DSR 71135.

The work was carried out in the Ralph M. Parsons Laboratory for Water Resources and Hydrodynamics of the Department of Civil Engineering at M.I.T. Mr. Ken Wilson, a Research Assistant in the Laboratory, assisted with the data reduction and numerous other essentials. 


\section{INTRODUCTION}

The design for a harbor in an exposed location generally includes a breakwater to provide an area sheltered from the waves. As breakwaters are usually designed to permit some overtopping by, the waves during severe storms, it becomes necessary to predict the characteristics of the waves so transmitted into the harbor, to assure that the wave action in the sheltered area is within acceptable limits. This report presents a theory for wave transmission by overtopping, based on an evaluation of the energy content of the overtopping water. While the coefficients for reflection and regeneration are open to question, the laboratory data shows that the general form of the equations developed is correct. Comparison with large-scale model tests reinforces this belief, and comparison of a theoretical prediction of the volume of overtopping water with a portion of the published data again shows reasonable agreement. An envelope curve for the transmission coefficient, based on data from several sources, gives a simple tool for preliminary estimates of the transmission coefficient.

\section{THEORY}

When a wave overtops a breakwater, some of the incident wave energy is reflected, some is dissipated, and some is transmitted past the breakwater into the sheltered area. Overtopping occurs 
when the wave runup on the seaward face of the breakwater exceeds the level of the breakwater crest. A slug of water from each incident wave overtopping the structure flows across the top and down the lee face of the breakwater; the transmitted waves are generated impulsively by this water mass, and thus the energy content of these transmitted waves must be derived from the overtopping water.

This energy content can be conveniently evaluated in steps: first, the energy content of the water as it crosses the breakwater crest must be estimated; next, the friction (and percolation) losses must be determined; and finally, the regeneration process must be studied.

The energy content of the overtopping water mass can be estimated by assuming that the total energy content of the overtopping water is the same as the energy of that portion of the wave runup that would lie above the breakwater crest were the breakwater face extended to-a higher elevation as shown in Fig. 1. At maximum runup, flow velocities are essentially zero, and all the energy of this water is in the form of potential energy. By knowing the shape and position of this hypothetical runup wedge, this potential energy can be calculated.

With the above assumptions stated, the solution to the problem can be outlined as follows:

I. The shape of the runup wedge is specified as an n-th degree parabola from the first seaward wave trough to the point of maximum runup on the extended breakwater face. 
II. Mass conservation requires that the volume of runup above the still water level (SWL) equals that "removed" in the trough, below the still water level, over the region from the first seaward wave trough (at maximum runup) to the breakwater.

III. The energy contained in the runup wedge is evaluated from the net energy flux into a control volume enclosing the runup wedge and the partial standing wave system just seaward of the breakwater.

IV. The overtopping energy is evaluated as the potential energy of that portion of the runup wedge extending above the actual breakwater crest elevation at maximum runup on the extended face.

V. The overtopping water volume is similarly evaluated as that portion of the runup wedge lying above the breakwater crest at maximum runup.

VI. The transmitted wave energy is evaluated by accounting for the net energy flux into a control volume which encloses the overtopping flow and the transmitted wave train. The above grouping provides a convenient means of summarizing the analytical details of the theory which follows.

While the analysis is for a two-dimensional section of the structure, with waves arriving at normal incidence to the structure, it should apply also to waves arriving nearly perpendicular to the breakwater. 


\section{Parabolic Runup Wedge}

At maximum runup, the shape of the runup wedge is assumed to be a parabola with its vertex at the bottom of the first wave trough. The corresponding equation is

$$
Y=M X^{n}-A
$$

where $\mathrm{Y}$ is the water surface elevation above the SWL, $\mathrm{X}$ is distance from the trough shoreward, and $\mathrm{A}$ is the amplitude at the trough (Fig. 1). This equation satisfies the conditions of surface continuity and slope at its vertex and approximates the shape of runup wedges observed in the laboratory. It will be assumed that maximum runup occurs in phase with the extremum in the partial standing wave profile. Using linear wave theory to describe the wave motion seaward of the first trough, A becomes

$$
\begin{aligned}
A & =A_{i}+A_{r} \\
& =A_{i}\left(I+k_{r}\right)
\end{aligned}
$$

where

$$
\begin{aligned}
& A_{i}=\text { incident wave amplitude } \\
& A_{r}=\text { reflected wave amplitude }
\end{aligned}
$$

$$
\text { and } k_{r}=\text { reflection coefficient* }
$$

The runup equation may be written in dimensionless form by dividing through by A, i.e.,

$$
\frac{Y}{A}=\frac{M L_{R}^{n}}{A}\left(\frac{X}{L_{R}}\right)^{n}-1
$$

where $L_{R}$ is the value of $X$ where $Y=R$, the runup height; thus,

* The symbol convention used throughout this paper is lower case letters represent dimensionless quantities and capital letters represent dimensional equivalents. 


$$
M L_{R}{ }^{n}=R+A
$$

and

$$
\frac{Y}{A}=\frac{R+A}{A}\left(\frac{X}{L_{R}}\right)^{n}-1
$$

The following dimensionless quantities are defined to simplify subsequent algebra: $\left(H_{b}, H, X_{1}, X_{2}\right.$, and $S$ are defined in Fig. 2).

$$
\begin{aligned}
& y, r, h_{b}, h, 1=\frac{Y}{A}, \frac{R}{A}, \frac{H_{b}}{A}, \frac{H}{A}, \frac{A}{A} \\
& x, x_{1}, x_{2}, s, 1=\frac{x}{L_{R}}, \frac{x_{1}}{L_{R}}, \frac{x_{2}}{L_{R}}, \frac{A S}{L_{R}}, \frac{L_{R}}{L_{R}}
\end{aligned}
$$

As a result, the dimensionless runup surface becomes

$$
y=(x+1) x^{n}-1
$$

\section{Conservation of Mass}

Referring to Fig. 2, mass conservation requires that the volume of water contained in the runup wedge between $x=x_{1}$ and $x=1$ equal volume missing from the void between $x=0$ and $x=x_{1}$. That is,

$$
\int_{0}^{1} y d x-\frac{s r^{2}}{2}=0
$$

Evaluating the integral yields,

or

$$
\left.\begin{array}{l}
\mathrm{n}=\frac{\mathrm{r}+1}{\frac{\mathrm{s} r^{2}}{2}+1}-1 \\
\mathrm{~s}=\frac{2}{\mathrm{r}^{2}} \frac{\mathrm{r}-\mathrm{n}}{\mathrm{n}+1}
\end{array}\right\}
$$

The physical limits on $\mathrm{n}$ are $\mathrm{n} \geq 1.0$ for the runup surface to be concave upward and $\mathrm{n}<\mathrm{r}$ for positive breakwater slopes. 
Equation (2) applies strictly to impermeable slopes, and will yield conservatively high estimates for overtopping volumes on permeable breakwaters.

\section{Energy Analysis - Seaward Face}

As the transmitted wave energy comes from the overtopping water, this overtopping energy, $E_{o}$ is unavailable to form the reflected wave. For the control volume of Fig. 3, the energy flux over a wave period $\mathrm{T}$ can be written,

$$
\text { Power in - Power out }=\text { Power loss }
$$

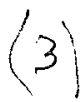

The power in is that of the incident wave. The power out includes that of the reflected wave and the overtopping water. The losses include friction losses on the slope and losses in the regeneration of the reflected wave.

If $\mathrm{PE}$ is defined as the potential energy of the entire runup wedge above SWL at maximum runup, then $P E-E_{0}$ is that portion of the runup energy which returns seaward via rundown.

Part of this returning energy is lost to surface friction and entrance losses in the rundown process. Independent studies at M.I.T. have enumerated the losses for a slug of fluid released down a smooth slope, (Sy, 1969, King, 1970). These studies indicated that reconversion of rundown energy to reflected (or transmitted) wave energy is very inefficient: if $\mathrm{E}$ is the potential energy of the slug at the onset of rundown, then the reconversion to wave energy results in energy losses equal to $k_{\ell} E$ where $k_{\ell}$ is a loss coefficient and

$$
0.65<k_{\ell}<0.85
$$

for a smooth slope of $1: 1.0$.

Recalling the energy flux relationships from linear wave theory, 
Equation (3) becomes

$$
E_{i} C_{\dot{g}}-E_{r} C_{g}-\frac{E_{O}}{T}=\frac{\left(P E-E_{O}\right) k_{\ell}}{T}
$$

where

$$
\begin{aligned}
C_{g} & =\text { energy propagation rate (group velocity) } \\
E_{i} & =\text { incident wave energy density } \\
& =\frac{\gamma}{2} A_{i}^{2} \\
\gamma & =\text { specific weight of fluid } \\
E_{r} & =\text { reflected wave energy density } \\
& =\frac{\gamma}{2} A_{i}^{2} k_{r}^{2}
\end{aligned}
$$

Let $T=\frac{L}{C}=\frac{\text { wave length }}{\text { ave celerity }}$

$$
\begin{aligned}
& \text { pe }=\frac{P E}{\gamma A^{2} L_{R}} \\
& e_{0}=\frac{E_{O}}{\gamma A^{2} L_{R}}
\end{aligned}
$$

where pe and $e_{0}$ are dimensionless potential energies, and $\mathrm{A}=$ $A_{i}\left(1+k_{r}\right)$ as previously defined. Substitution of the above into Equation (4) yields

$$
p e+e_{o}\left(\frac{1}{k_{\ell}}-I\right)=\frac{C_{g}}{C} \frac{L}{L_{R}} \cdot \frac{1}{2 k_{\ell}} \frac{\left(1-k_{r}{ }^{2}\right)}{\left(1+k_{r}\right)^{2}}
$$

where $k_{r}$ is reflection coefficient of the overtopped structure. This will be taken as a linear interpolation between Miches reflection coefficient, $k_{m}$, for a structure whose height exceeds maximum runup, and zero reflection for no structure. That is,

$$
k_{r}=k_{m} \frac{\left(h+h_{b}\right)}{(h+r)}
$$


Equation (6) may be interpreted as a reduction in the reflection coefficient by a factor which is proportional to the fictitious breakwater extension. Presently available information about partial reflection from overtopped structures does not justify a more elaborate relationship.

The potential energy of the runup wedge must be evaluated relative to its ability to return work to the reflected wave system. The reconversion of runup potential energy to wave energy occurs in two steps: (1) The potential energy of the slug is converted to kinetic energy as the slug falls to the water surface, and (2) this kinetic energy is converted to fluid motion in the re-entrance vicinity. Much of the induced fluid motion is turbulent and is eventually lost to viscous dissipation (as accounted for by the loss coefficient, $k_{\ell}$ ). The remaining motion contributes to a component of the reflected wave. It is important to note, however, that once the center of gravity of the slug flow has entered the water, the slug is neutrally bouyant and therefore has no further potential to accelerate. The reconversion energy is limited to the kinetic energy gained by the slug in falling to the water surface. Consequently, at maximum runup the potential energy should be measured relative to the water surface. Due to the uncertainty of position of the water surface during re-entrance, the potential energy will be evaluated with respect to the SWL.

It follows directly that the dimensionless potential energy of the runup wedge at maximum runup is simply (see Fig. 2), 


$$
p e=\int_{x_{1}}^{1} \frac{y^{2}}{2} d x-\frac{s r^{3}}{6}
$$

At $\mathrm{x}=\mathrm{x}_{1}, \mathrm{y}=0$

thus $x_{1}=\left(\frac{1}{x+1}\right)^{1 / n}$

and completing the above integration yields

$$
\begin{aligned}
& \text { pe }=\frac{1}{2}\left\{\frac{(r+1)^{2}}{2 n+1}\left[1-\frac{1}{(r+1)^{2}+1 / n}\right]-\right. \\
& \frac{2(r+1)}{n+1}\left[1-\frac{1}{(r+1)^{1+1 / n}}\right]+ \\
& {\left.\left[1-\frac{1}{(r+1)^{1 / n}}\right]-\frac{s r^{3}}{3}\right\} }
\end{aligned}
$$

\section{Overtopping Energy}

As described earlier, the overtopping energy is equal to the potential energy of that portion of the runup wedge extending above the breakwater crest. The potential energy is evaluated with respect to the SWL, thus

$$
e_{0}=\int_{x_{2}}^{1}\left(y-h_{b}\right)\left(h_{b}+\frac{y-h_{b}}{2}\right) d x-\frac{s\left(r-h_{b}\right)^{2}}{2}\left(h_{b}+\frac{r-h_{b}}{3}\right)
$$

At $x=x_{2}, \quad y=h_{b}$ thus $x_{2}=\left(\frac{h_{b}+1}{r+1}\right)^{1 / n}$

Completing the above integration yields 


$$
\begin{aligned}
& e_{0}=\frac{1}{2}\left\{\frac{(r+1)^{2}}{2 n+1}\left[1-\left(\frac{h_{b}+1}{r+1}\right)^{2+1 / n}\right]-\right. \\
& \frac{2(r+1)}{n+1}\left[1-\left(\frac{h_{b}+1}{r+1}\right)^{1+1 / n}\right]+ \\
& \left(1-h_{b}^{2}\right)\left[1-\left(\frac{h_{b}+1}{r+1}\right)^{1 / n}\right]- \\
& \frac{s}{3} \quad\left(r-h_{b}\right)^{2}\left(r+2 h_{b}\right)
\end{aligned}
$$

Substitution of Equations (7) and (8) into Equation (5) completes the energy conservation analysis on the seaward side of the breakwater.

\section{Overtopping Volume}

The overtopping volume is evaluated from Fig. 2 as that volume in the runup wedge which extends above the breakwater crest. That is,

$$
\forall=\int_{x_{2}}^{1}\left(y-h_{b}\right) d x-\frac{s\left(r-h_{b}\right)^{2}}{2}
$$

Evaluating the integral yields

$$
\begin{aligned}
\forall= & \left(\frac{r+1}{n+1}\right)\left[1-\left(\frac{h_{b}+1}{r+1}\right)^{1+1 / n}\right]- \\
& \left(1+h_{b}\right)\left[1-\left(\frac{h_{b}+1}{r+1}\right)^{1 / n}\right]-\frac{s\left(r-h_{b}\right)^{2}}{2}
\end{aligned}
$$




\section{Transmitted Wave Energy}

Energy conservation requires that during each wave period the net energy accumulated in the control volume sketched in Fig. 4 sums to zero, i.e.,

$$
\text { power in }- \text { power out }=\text { power loss }
$$

The energy flux into the control volume is simply the overtopping energy divided by the wave period. The power loss equals the overtopping energy flux multiplied times the rundown loss coefficient, $k_{\ell}$. The energy flux passing out of the control volume is that associated with the transmitted wave. Although the regeneration process is quite complex, it repeats periodically at the frequency of the incident wave, and thus the fundamental mode of the transmitted wave has the same frequency as the incident wave. Experiments at M.I.T. indicate that this mode contains most of the transmitted wave energy. As a first approximation, then, higher harmonics may be neglected and the power leaving the control volume during one wave period is simply $\mathrm{E}_{\mathrm{t}} \mathrm{C}_{\mathrm{g}}$ where

$$
E_{t}=\frac{\gamma A_{i}^{2}}{2} k_{t}^{2} C_{g}
$$

and $k_{t}=\frac{A_{t}}{A_{i}}=$ transmission coefficient. Substituting the above into Equation (10) yields

$$
\frac{E_{\mathrm{o}}}{\mathrm{T}}-\frac{\gamma \mathrm{A}_{\mathrm{i}}^{2}}{2} \cdot \mathrm{k}_{\mathrm{t}}^{2} \cdot \mathrm{C}_{\mathrm{g}}=\frac{\mathrm{E}_{\mathrm{O}}}{\mathrm{T}} \mathrm{k}_{\ell}
$$

But $E_{O}=A_{i}^{2}\left(1+k_{r}\right)^{2} \cdot L_{R^{\prime}} e_{o}$ and $T=\frac{L_{t}}{C}$, where $L_{t}=$ transmitted wave length. 
If the water depth on the lee side of the breakwater is the same on the seaward side, then $L_{t}=L$ and

$$
\mathrm{k}_{\mathrm{t}}^{2}=2 \mathrm{e}_{\mathrm{o}} \frac{\mathrm{C}}{\mathrm{C}_{\mathrm{g}}} \frac{\mathrm{L}_{\mathrm{R}}}{\mathrm{L}}\left(1+\mathrm{k}_{\mathrm{r}}\right)^{2}\left(1-\mathrm{k}_{\ell}\right)
$$

The problem as defined includes five dimensionless unknowns: $n, r, k_{r}, k_{t}$ and $s\left(\right.$ or $L_{R}$ ). However, only four equations have been presented to facilitate the solution to the above. The pertinent equations are (2), (5), (6), and (11). A11 other quantities of interest are functions of the five fundamental dependent variables listed. A fifth relationship is needed to completely specify the problem. Two alternative requirements have been explored to satisfy the need for a fifth equation.

The first attempt required that the runup wedge be tangent to the extended breakwater slope at the height of maximum runup. This is a condition which has been observed for gentle slopes. This restraint, however, yields runup heights exceeding those observed by a factor of 1.5 and greater.

The second attempt specified that the distance from the breakwater to the first trough be equal to half a modified wave length. The modified wave length is computed from linear wave theory as a function of water depth on the breakwater slope, and is defined as the integrated average wave length in the interval between the first trough and the intersection of the SWL with the breakwater slope. This requirement reduces to known results for the two extreme conditions of vertical walls and horizontal slopes. Imposing this restraint, however, yields runup heights which fall short of those observed experimentally by a factor 
of 0.7 and less. Corresponding transmission coefficients are similarly low.

To satisfy the immediate need for a fifth equation, the authors have relied on Saville's experimental results (B.E.B. T.M. 非4) as an input for runup heights. As a specific example, for a smooth impermeable slope of $1: 1.5$, wave height to water depth ratios in excess of 3.0 , and wave cambers near 0.05 , the appropriate runup height is twice the incident wave height. Use of Saville's runup ratios for high breakwater crests $\left(h_{b} / r>0.5\right)$ yields good correlation between experimental and theoretical transmission coefficients. However, for relatively low breakwater crests $\left(h_{b} / r<0.05\right)$ Saville's data underestimates the equivalent runup height, and predicted transmission coefficients are somewhat low. It should be pointed out that this latter category is of little interest for practical breakwater design.

Summarizing, the five dimensionless unknowns, $\mathrm{n}, \mathrm{r}, \mathrm{k}_{\mathrm{r}}, \mathrm{k}_{\mathrm{t}}$, and s may be solved using Saville's experimental runup heights and Equations (2), (5), (6), and (11). Equations (7) and (8) must be utilized to find pe and $e_{o}$ in terms of the five unknowns. An iterative procedure is employed in seeking a solution which satisfies all five conditions simultaneously. The authors have found that this is most quickly accomplished by incrementing $n$ up from a minimum value of unity until Equations (2), (5) and (6) are satisfied and then solving directly for the transmission coefficient and the overtopping volume. A simple digital computer program has been written in FORTRAN IV G to expedite this solution. 


\section{EXPERIMENTAL EQUIPMENT}

The experiments were performed at M.I.T. by Lamarre (1967), using a glass-walled wave flume 2.5 feet wide and 105 feet long, using a constant water depth of 1.5 feet. At the far end of the flume was an impervious beach at a $5 \%$ slope.

The wave generator was of the flap type, 2.5 feet high, and hinged at the bottom; the top was moved back and forth by a rod attached to a crank arm having variable speed and eccentricity. The smooth, impermeable breakwater was located 51.5 feet from the wave generator and was 1.3 feet high. It could be raised by small increments to a maximum height of 1.77 feet by adding blocking underneath. These blockings were made of wood, shaped and installed in such a way as to maintain constant front and rear slopes of 1 vertical to 1.5 horizontal. The horizontal crest of the breakwater was 0.33 feet wide. Roughness was obtained when desired by adding flattened expanded metal lath sheets on top of the smooth surfaces.

The instruments used in the experiment were parallel-wire resistance type wave gages connected by a wheatstone bridge to a twochannel Sanborn recorder. The wave gages consisted of two vertical stainless steel wires $1 / 8^{\prime \prime}$ in diameter and 1 foot long, mounted from above 3/4" apart, and partially immersed in the water.

\section{EXPERIMENTAL PROCEDURE}

Six different wave periods were investigated. Once the frequency of the wave generator was adjusted to the proper value, and before inserting the breakwater into the flume, the eccentricity of the driver crank was set at four different positions and the corresponding 
"incident" waves generated at each setting were recorded.

After the recording of these incident waves was completed, the breakwater was installed, and two wave gages were mounted at distances of one and two wavelengths respectively beyond the centerline of the structure. The four different incident waves already measured were then reproduced and the transmitted waves recorded. All the experiments were repeated after adding the expanded metal sheet for roughness.

The complete series of tests was made for each increase in the height of the breakwater. After the breakwater was at its maximum height, i.e., when there was no more overtopping, the structure was pulled out of the water, the frequency of the wave-maker changed, and the process repeated for five more periods.

\section{EXPERIMENTAL RESULTS AND DISCUSSION}

The transmitted wave heights measured by gages 1 and 2 were averaged to obtain an estimate of "the" transmitted wave height. Due to the presence of the higher harmonics in the transmitted wave system, there was generally some variation between the wave heights measured at the two locations; this variation typically amounted to 5 to 15 percent. The incident wave height is similarly taken as the average of the two wave gages, but the difference only amounts to a percent or two. Similar effects were noted by the U. S. Army Corps of Engineers (1965) in the Dana Point mode1 tests.

The data are shown in Figs. 5 through 10 as $k_{t}$ vs $H_{b} / R$ for all 
experimental runs, The curves plotted are solutions to Eq. I1 and depict theoretical bounds for smooth and rough surfaces. The smooth surface curve corresponds to a runup ratio $\mathrm{R} / \mathrm{H}_{i}=1.8$, a loss coefficient $k_{\ell}=0.6$, and an "intrinsic" coefficient of reflection (as described by Miche) $\rho=0.8$. The rough surface curve cprresponds to $\mathrm{R} / \mathrm{H}_{i}=1.6, \mathrm{k}_{\ell}=0.8$ and $\rho=0.7$.

The runup ratios used are those indicated by our own studies. They are somewhat lower than those suggested by Saville $\left(\mathrm{R} / \mathrm{H}_{\mathrm{i}} \simeq 2.0\right)$ and probably include some scale effects as well as peculiarities of the experimental apparatus.

The loss coefficient values follow directly from sy's experiments. He found for a smooth $1: 1$ slope an average $k_{\ell} \simeq 0.7$. It is felt that the regeneration process is more efficient for horizontal momentum transfer (as in a wave generator flap) than for vertical momentum transfer. Since the horizontal component of rundown momentum increases for decreasing slopes one might expect smaller loss coefficients for more gradual slopes. There is, of course, a trade off to surface friction on very gradual slopes but for smooth $1: 1.5$ slopes a loss coefficient equal to 0.6 seems appropriate. This is increased to 0.8 for the equivalent roughened slope.

The intrinsic coefficient of reflection is a function of surface roughness and permeability. Miche suggests a value of $\rho=0.8$ for smooth impermeable slopes, and $\rho^{2} 0.33$ for rubble slopes. Consequently a value of 0.8 was chosen for the smooth slope and 0.7 for the rough slope. For deep water wave cambers $\mathrm{H}_{\mathrm{O}} / \mathrm{L}_{\mathrm{O}}<0.06$ and $1: 1.5$ 
slopes, Miche's theory yields $k_{m}=\rho$.

For low breakwaters $\mathrm{H}_{\mathrm{b}} / \mathrm{R}<0.3 \pm$ the theory underestimates the transmission coefficient; it appears reasonable that the assumptions underlying the theory are least valid in this region, and moreover, the values of $\mathrm{K}_{\mathrm{r}}$ and $\mathrm{k}_{\ell}$ used may not be applicable. However, this range of $H_{b} / R$ is of little practical interest, as the transmission coefficients are typica11y 0.3 to 0.6 .

For higher breakwaters $\left(H_{b} / R>0.5 \pm\right)$, the theory generally overestimates the transmission coefficient, particularly for the smaller values of relative depth, H/L. For the most of the range of $\mathrm{H} / \mathrm{L}$ however, the theory provides an "upper envelope" for $k_{t}$, and thus is useful for preliminary design estimates.

It is interesting to note on Figs. 5 through 10 that the incident wave steepness, $\mathrm{H}_{i} / \mathrm{L}$ has 1 ittle effect on the transmission coefficient except at the lowest values of $\mathrm{H}_{i} / \mathrm{L}$.

As one might expect, adding roughness to the slopes reduces the transmission coefficient for the laboratory data, probably by reducing the runup and increasing $k_{\ell}$.

There is a significant amount of scatter in the data; this can be attributed to several sources.

1. Wave gage inaccuracies; these gages typically are only good to 5 to 10 percent.

2. Lateral resonance effects can bias readings taken along the channel centerline. For several runs, it was noticed that the wave crests were not uniform across the channel. For the 1.5 second waves, the channel width is close to a 
quarter-wave-1ength and for the 1.0 second waves, a half-wave-length. For the other periods, however, especially with steeper waves, the partial breaking occasionally observed on the structure can generate higher harmonics capable of lateral resonance.

3. Breaking of the waves on the structure, observed for the steeper waves, causes an additional energy loss not accounted for by the theory. Because of the strong dependence of breaker characteristics on the backwash from the preceding wave, no very uniform effect of breaking can be expected.

Besides the scatter, another shortcoming of the data is that the ranges of relative depth, $\mathrm{H} / \mathrm{L}$, and wave steepress, $\mathrm{H}_{\mathrm{i}} / \mathrm{L}$, do not fully cover those found in the prototype. Breakwaters are typically built in 15 to 40 feet of water, and the incident waves typically have wave lengths from 200 to $400 \mathrm{ft}$; thus $\mathrm{H} / \mathrm{L}$ ranges from approximately 0.04 to 0.2 in the prototype, while $\mathrm{H} / \mathrm{L}$ in the experiments ranges from 0.16 to 0.45. Similarly the wave steepness $H_{i} / L$, in the prototype under storm conditions will be approximately 0.04 to 0.10 , while the maximum steepness available in the experiments was 0.064 . These difficulties stem from the difficulty of generating steep waves in shallow water with a hinged-flap wave generator. The Dana Point data (Fig. 11), however, represents prototype conditions, and agrees we11 with the laboratory data, suggesting that depth is not a very important factor, except possibly for waves which break before reaching the structure.

Figure 11 provides a comparison between theory and experiment for 
a more realistic breakwater form. The experimental data are from the U. S. Army Corps of Engineers Report describing a series of scale model tests for the design of a harbor at Dana Point, California. As the Dana Point breakwater was a permeable structure, some wave energy was transmitted even with no overtopping $\left(k_{t}<0.1\right)$, and thus, the transmitted wave heights given for sma11 amounts of overtopping were not included. The runup ratios used for the Dana Point data were $\mathrm{R} / \mathrm{H}_{\mathrm{i}}=1.0$ and 1.1 for prototype wave periods of 12 and 18 seconds respectively. These ratios were estimated from the data for non overtopping waves but agree well with Saville's results. The theoretical points correspond to the runup ratios stated above, loss coefficient $k_{\ell}=0.8$, and intrinsic coefficient of reflection $\rho=0.4$.

Referring to Fig. 11 it is evident that a scale effect exists. The 1:50 scale model yields larger transmission coefficients than the 1:5 scale mode1. This is probably a Reynolds effect wherein the re-entrance losses for the larger, more turbulent model (and therefore prototype) are higher than in the smaller model. The theoretical solution lies between the two experimental results. Extrapolating these results to prototype scale, one expects the theory to give a conservatively high estimate for the transmission coefficient. For engineering purposes, however, this is a desirable condition.

The theory does not account for direct transmission through a permeable breakwater. The continuity equation, Eq. (2), neglects flow into the pores of the breakwater and thereby overestimates the overtopping volume. Consequently, the transmission coefficient due 
to pure overtopping is also overestimated. The two errors are compensating. However, the overtopping regeneration process appears to be more efficient than direct transmission through breakwaters of low permeability. The net result is that the transmission coefficient is slightly overestimated when the overtopping theory is applied to rubble mound breakwaters. Again, this is a desirable condition for engineering estimates.

All of the experimental data, including Dana Point, are presented in Fig. 12, It demonstrates the validity of using $\mathrm{H}_{b} / \mathrm{R}$ as the dimensionless parameter for plotting overtopping transmission data. The envelope curve is of considerable interest as it appears to be a fairly consistent upper bound for the transmission coefficient, of the form

$$
k_{t}=0.65\left(1.10-H_{b} / R\right), \text { for } H_{b} / R<1.0
$$

Saville (1955) has published data on flow rates associated with the overtopping of various coastal structures. By multiplying the given discharges (cfs/ft of crest width) by the wave period, an overtopping volume per wave is obtained. These results can be compared with Eq. (9). Fig. 13 shows Eq. (9) plotted dimensionlessly as $\forall /\left(R-H_{b}\right)^{2}$ (where $\forall=L_{R} A \forall$, the dimensional overtopping volume per foot of breakwater crest) vs Saville's results. The data shown are for a structure with a smooth face on a $1: 1.5$ slope, for the depths of 4.5 and 9.0 feet at the toe, wave periods of 2.96 to 6.4 seconds, and for runup ratios, based on non-overtopping wave data, ranging from 2.54 to 3.57 . Breaking waves and waves with 1ittle overtopping have 
been neglected. For the latter the heights and runups are reported only to the nearest foot, and the small values of $R-H_{b}$ computed are not reliable. The theoretical points solved for used the given runup ratios, $k_{\ell}=0.7$ and $\rho=0.8$. The correlation between theory and experiment (perfect correlation is the $45^{\circ}$ line) further supports the analytical assumptions. Again the theory conservatively overestimates the volumes, a probably consequence of the high runup ratios used.

\section{CONCLUSIONS}

The theory presented describes the essential features of the process of wave transmission by overtopping, for waves arriving at the breakwater without breaking and at normal incidence. The relationship derived is dependent on the coefficients of reflection and loss, and the runup ratio. Further investigation of these quantities would permit a refinement of the theory.

The envelope curve may be used for preliminary estimates of the transmission coefficient. For rubble mound breakwaters this estimate can be improved by using the theory along with a runup ratio $\mathrm{R} / \mathrm{H}_{\mathrm{i}}=1.0$, a loss coefficient $\mathrm{k}_{\ell}=0.8$, and an intrinsic reflection coefficient $\rho=0.4$. 


\section{REFERENCES}

U. S. Army Corps of Engineers (1966), "Shore Protection, Planning and Design", Coastal Engineering Research Center, Technical Report No. 4, Third Edition, U. S. Government Printing Office.

Miche, R., (1953), "The Reflecting Power of Maritime Works Exposed to Action of the Waves", Bull. Beach Erosion Board, U. S. Army Corps of Engineers, Vo1. 7, No. 2, Apri1 1953, p. 1-7.

Sy, T., (1969), Personal Communication

King, N., (1970), "Wave Regeneration in Breakwater Overtopping", S. M. and Ocean Engineer Thesis submitted to the Department of Naval Architecture and Marine Engineering, M.I.T., Cambridge, Mass., August 1970.

U. S. Army Corps of Engineers (1965), "General Design for Dana Point Harbor, Dana Point, California", September 1965.

Saville, T., Jr., (1955), "Laboratory Data on Wave Runup and Overtopping on Shore Structures", U. S. Army Corps of Engineers, Beach Erosion Board Technical Memorandum No. 64.

Lamarre, P., (1967), "Water Wave Transmission by Overtopping of an Impermeable Breakwater", S. M. Thesis submitted to the Department of Civil Engineering at M.I.T., Cambridge, Mass.,

September 1967. 


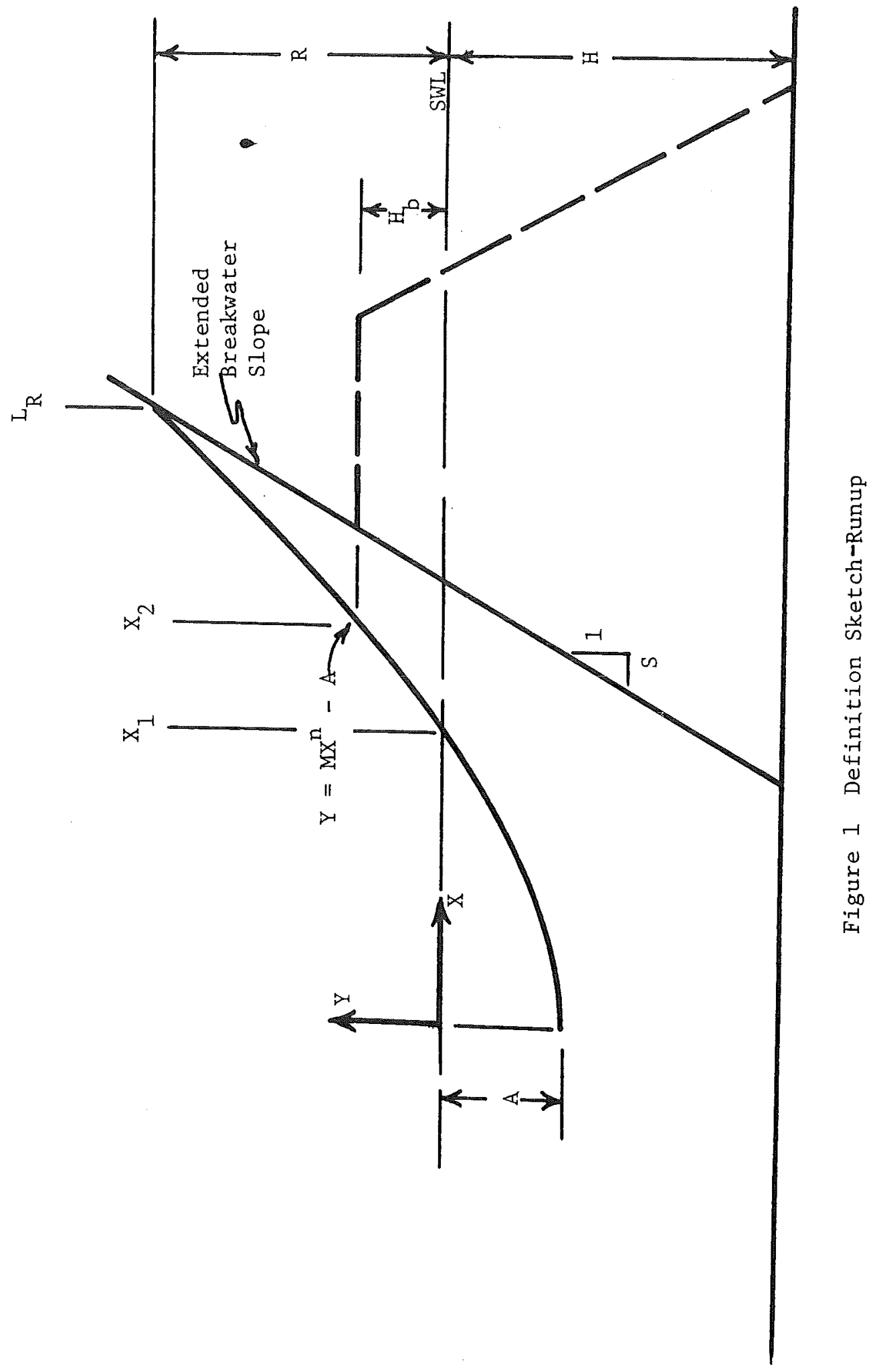




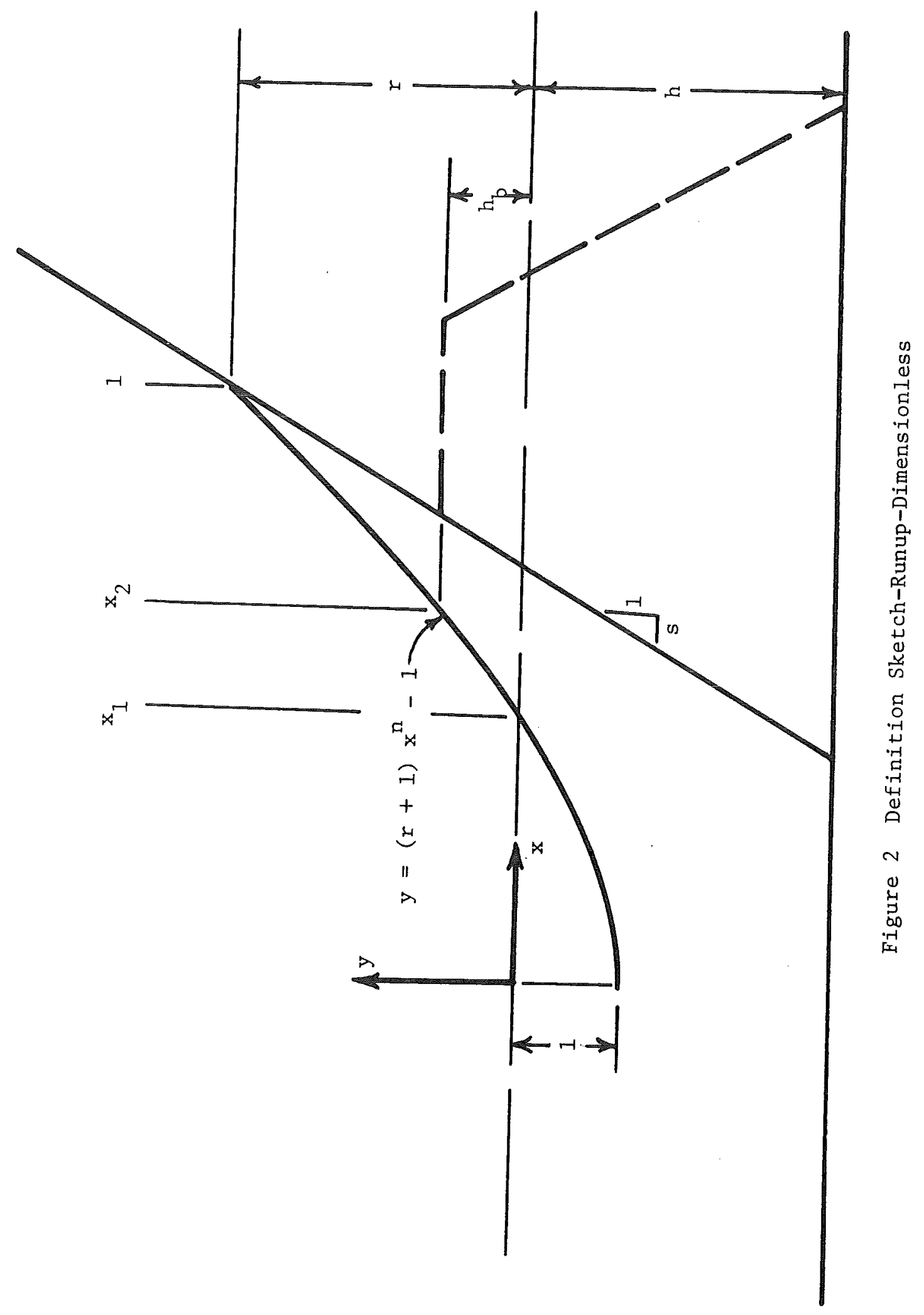




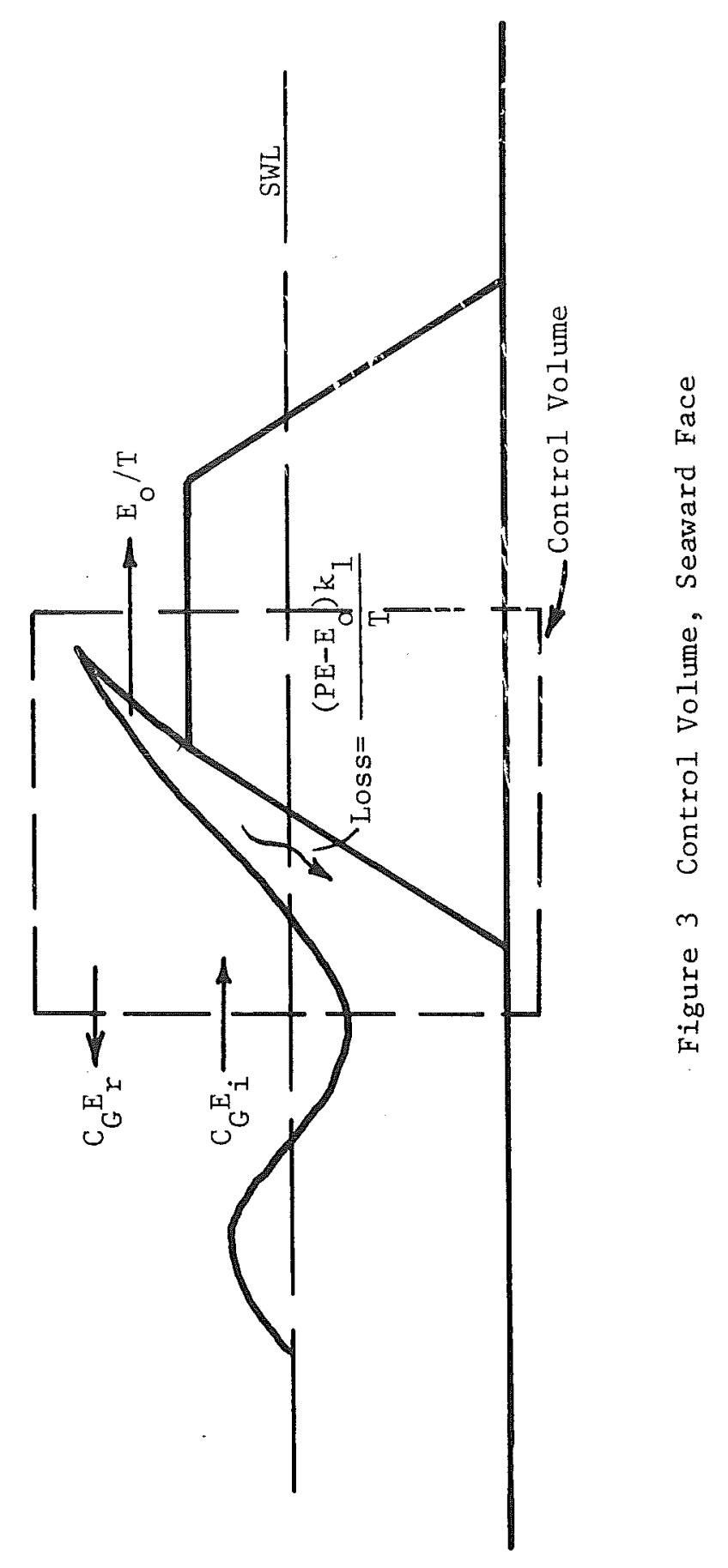




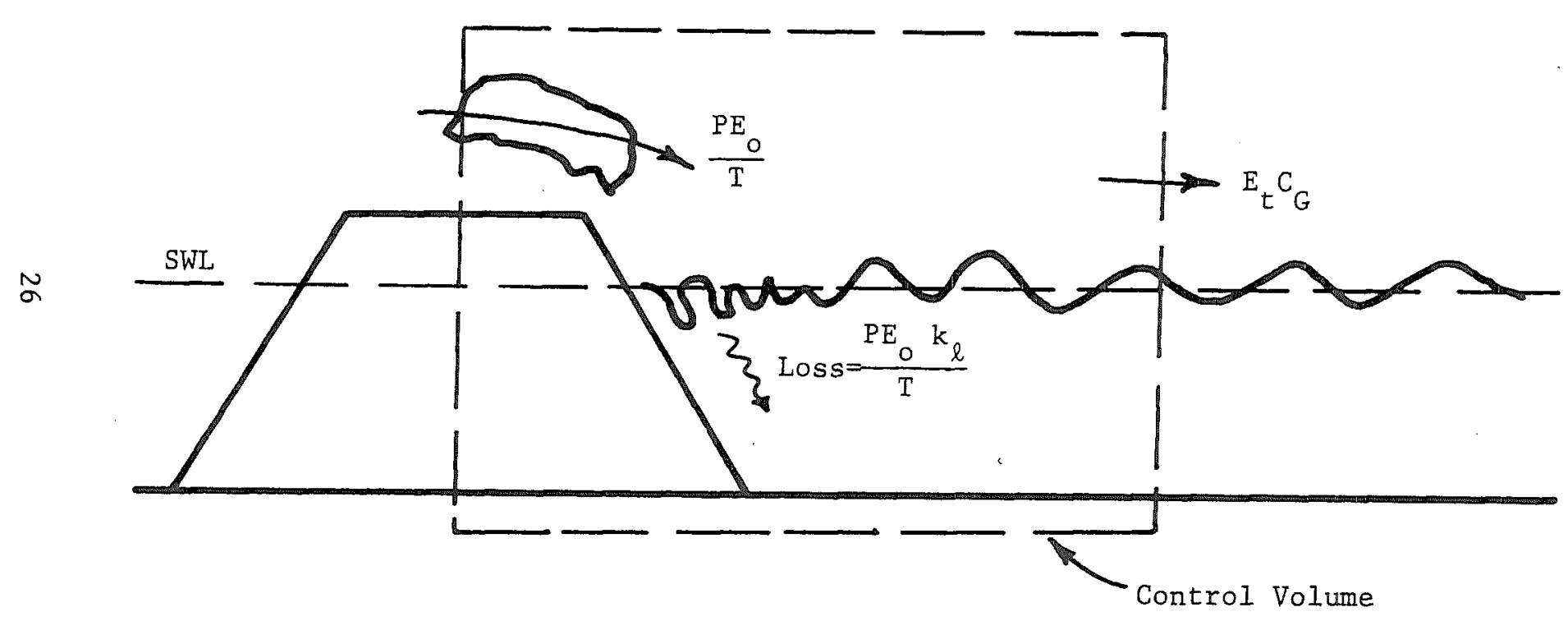

Figure 4 Control Volume, Leeward Face 


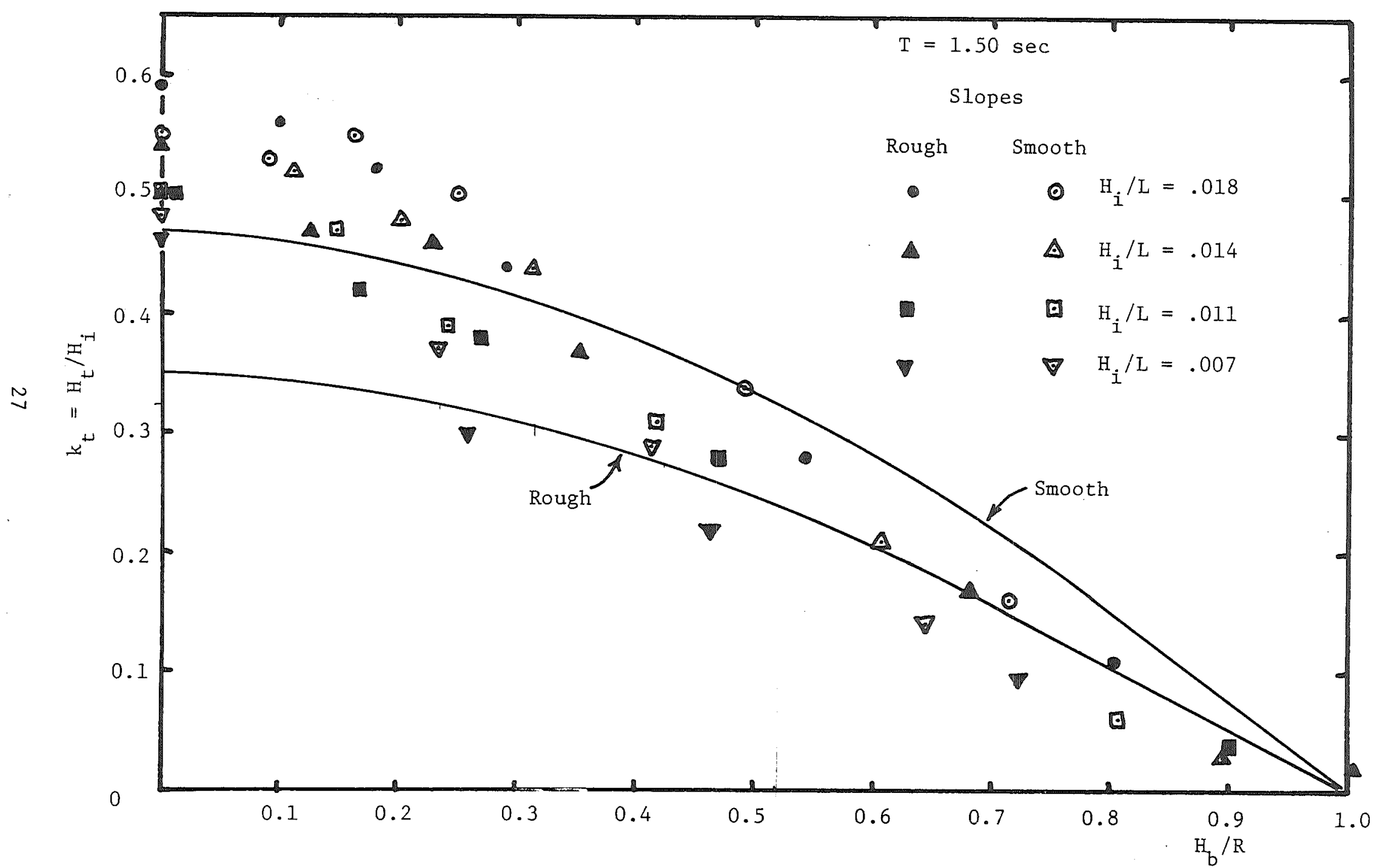

Figure $5 \mathrm{k}_{t}$ vs $\mathrm{F}_{\mathrm{b}} / \mathrm{R}, \quad \mathrm{T}=1.5 \mathrm{sec}$ 


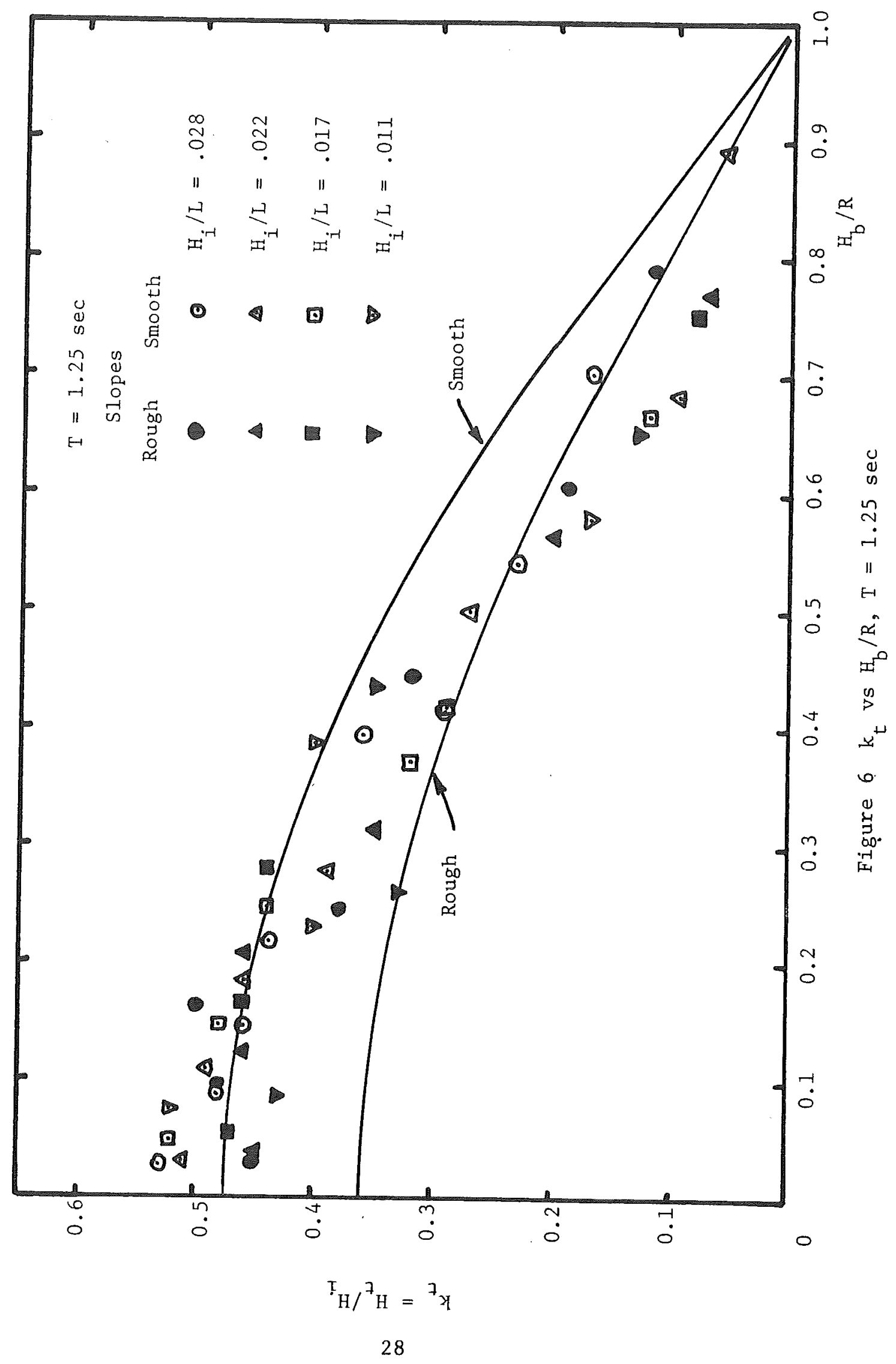




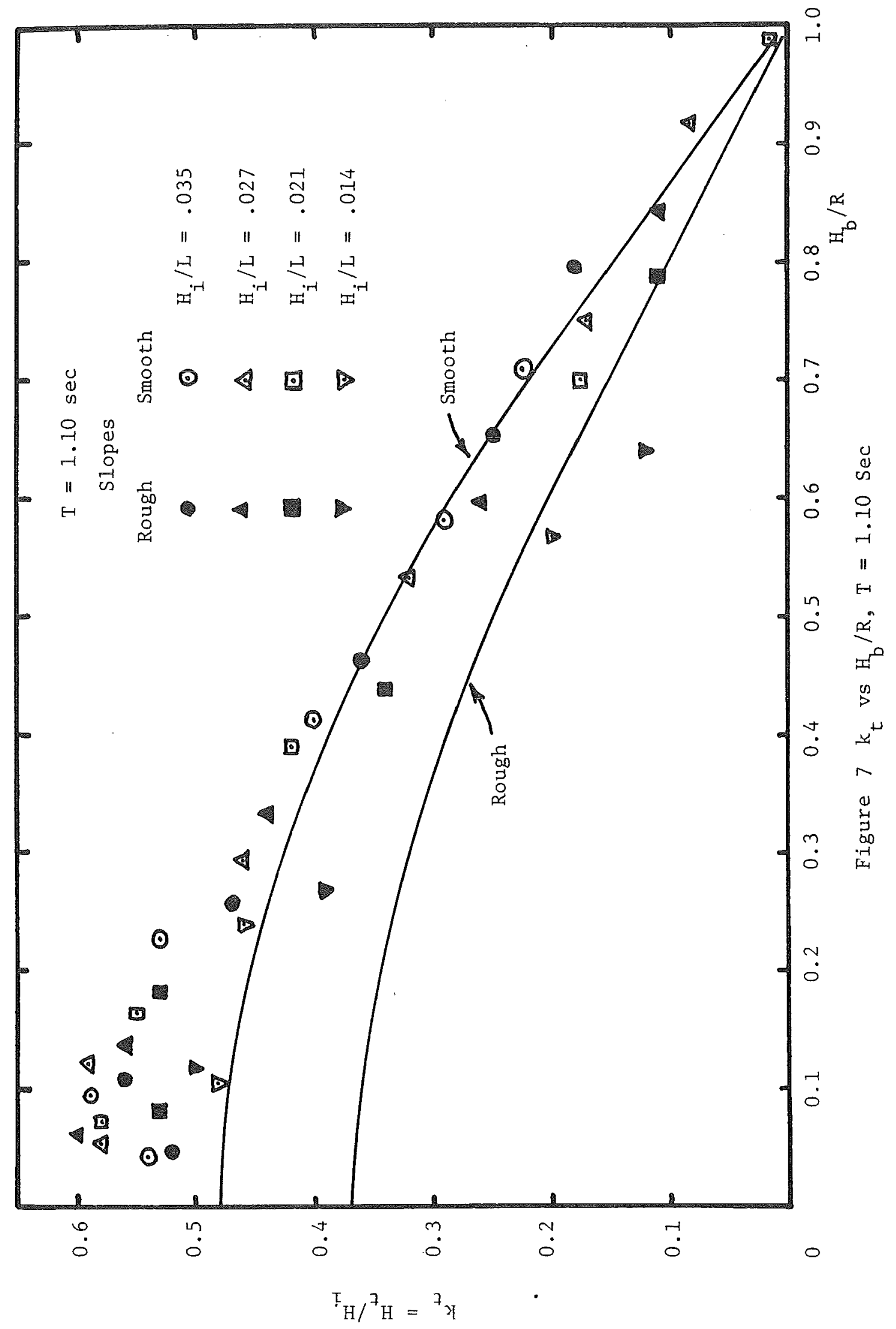




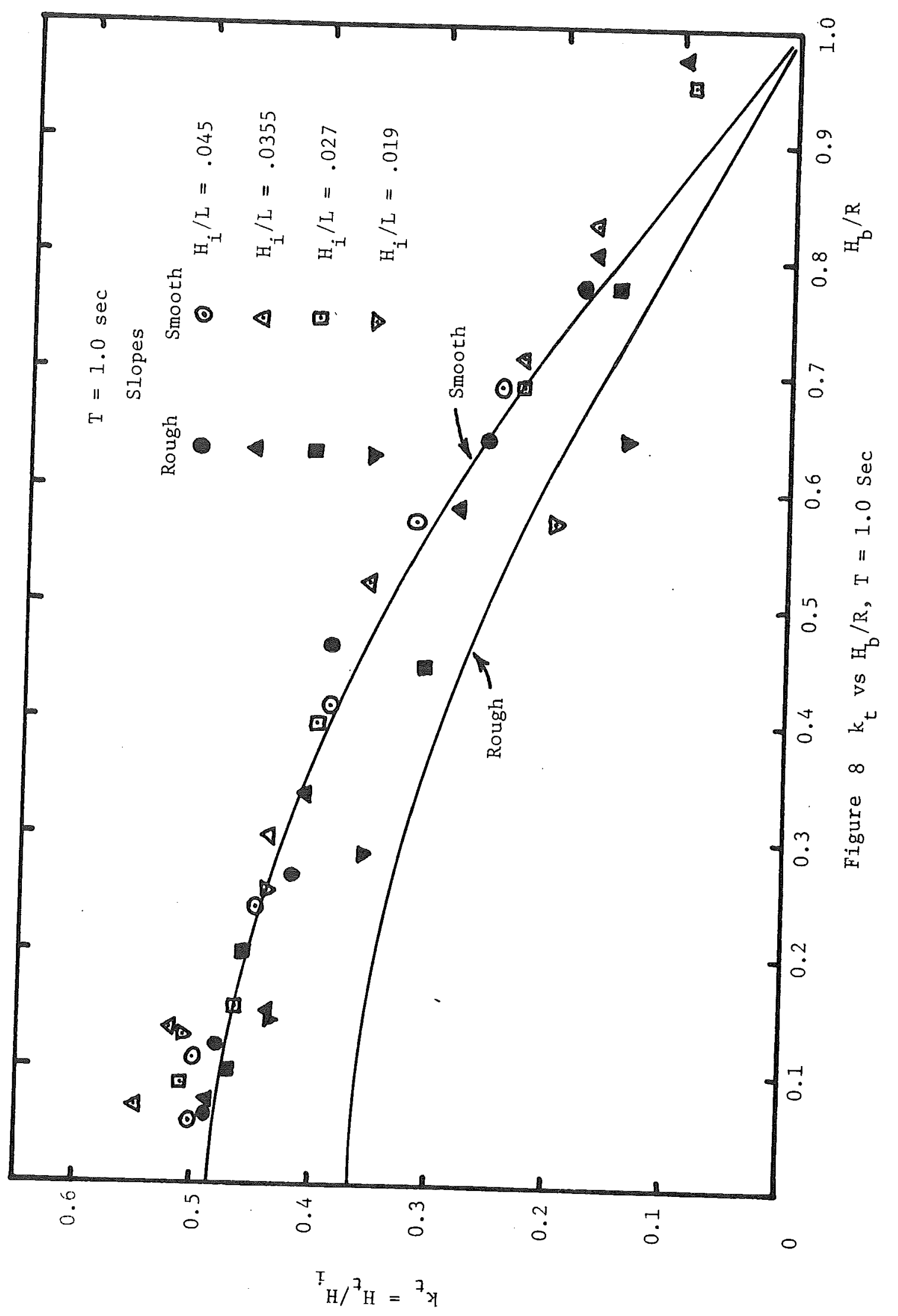




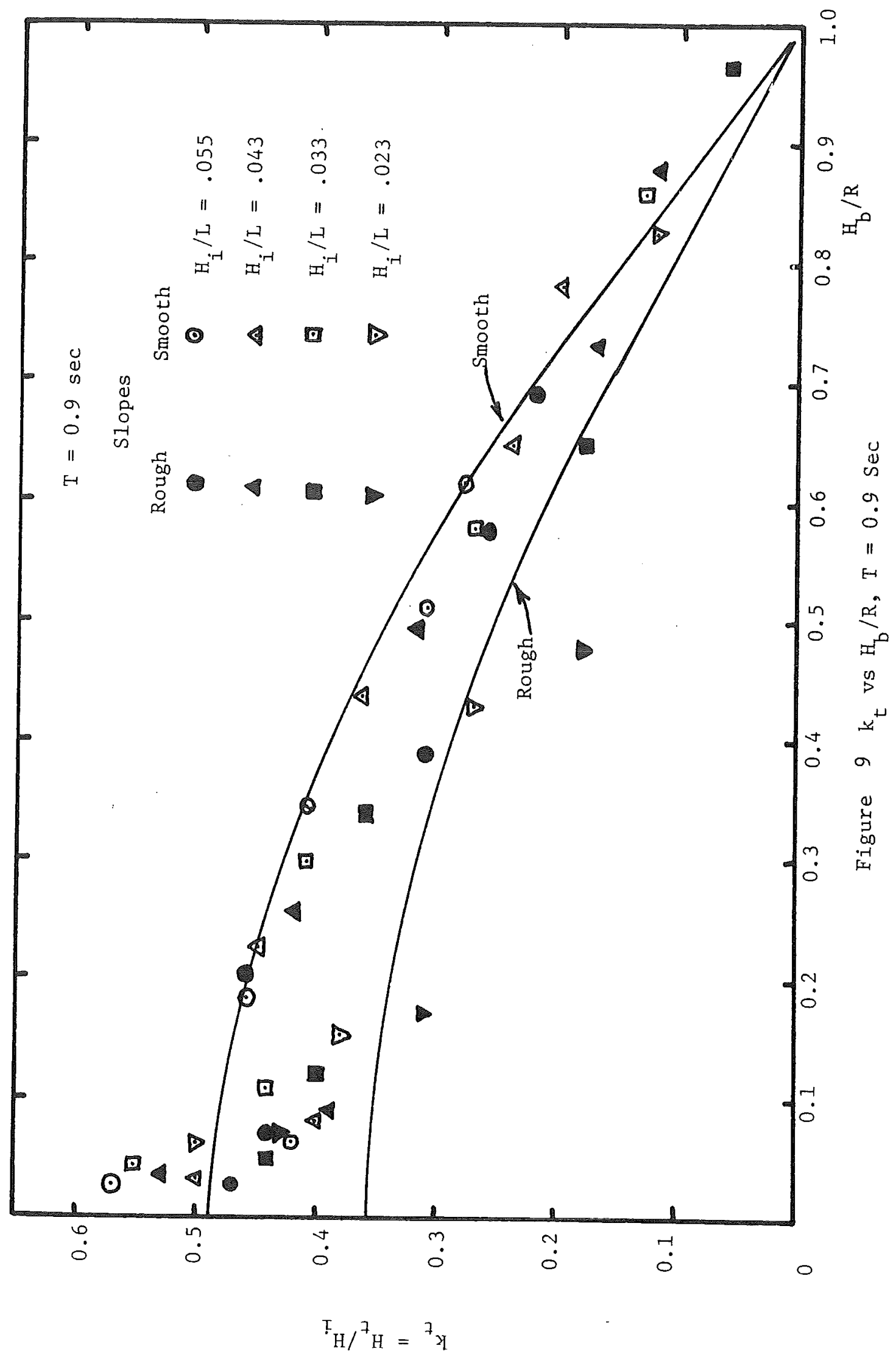




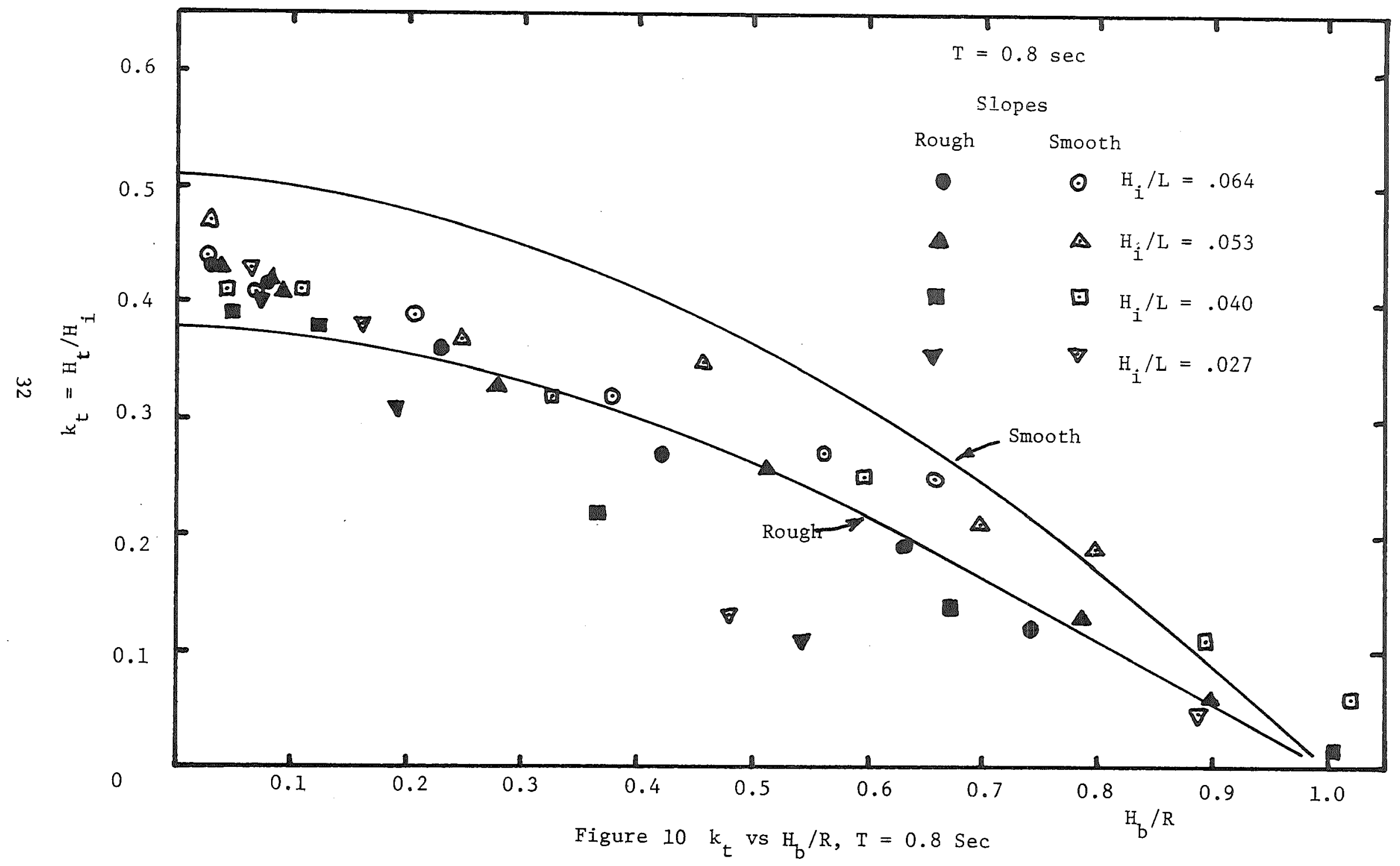




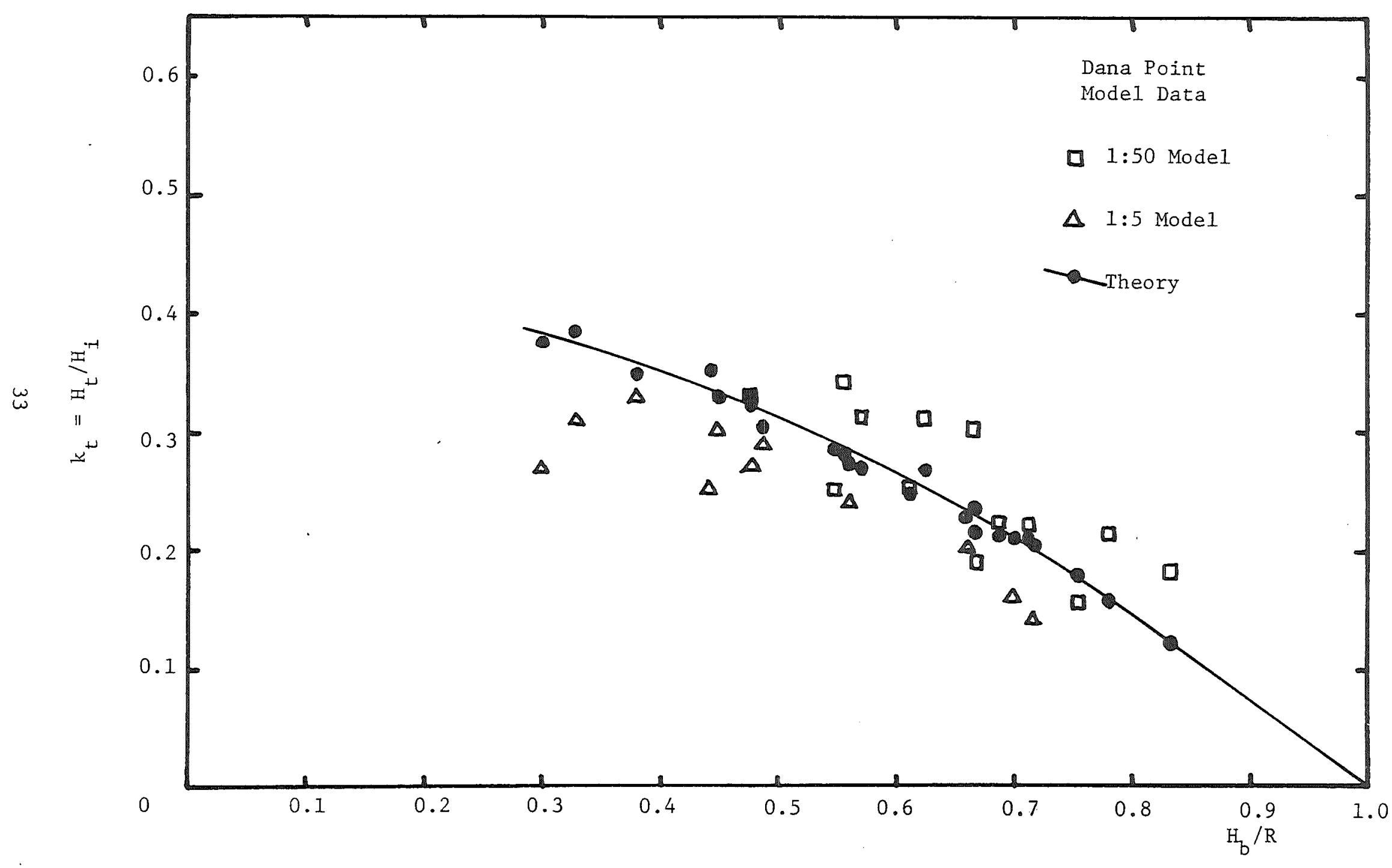

Figure $11 k_{t}$ vs $H_{b} / R$ - Dana Point Model Data and Theory 


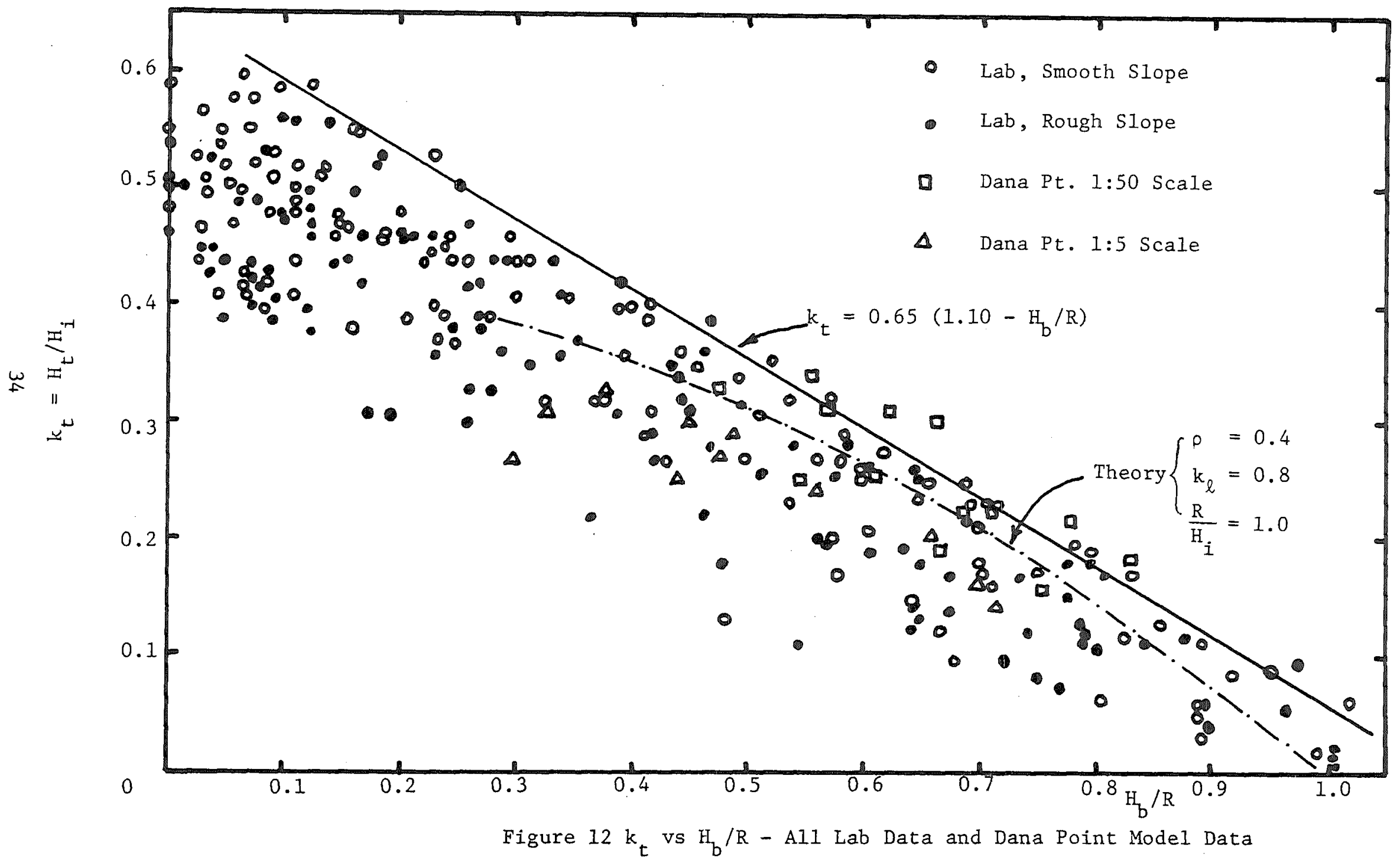




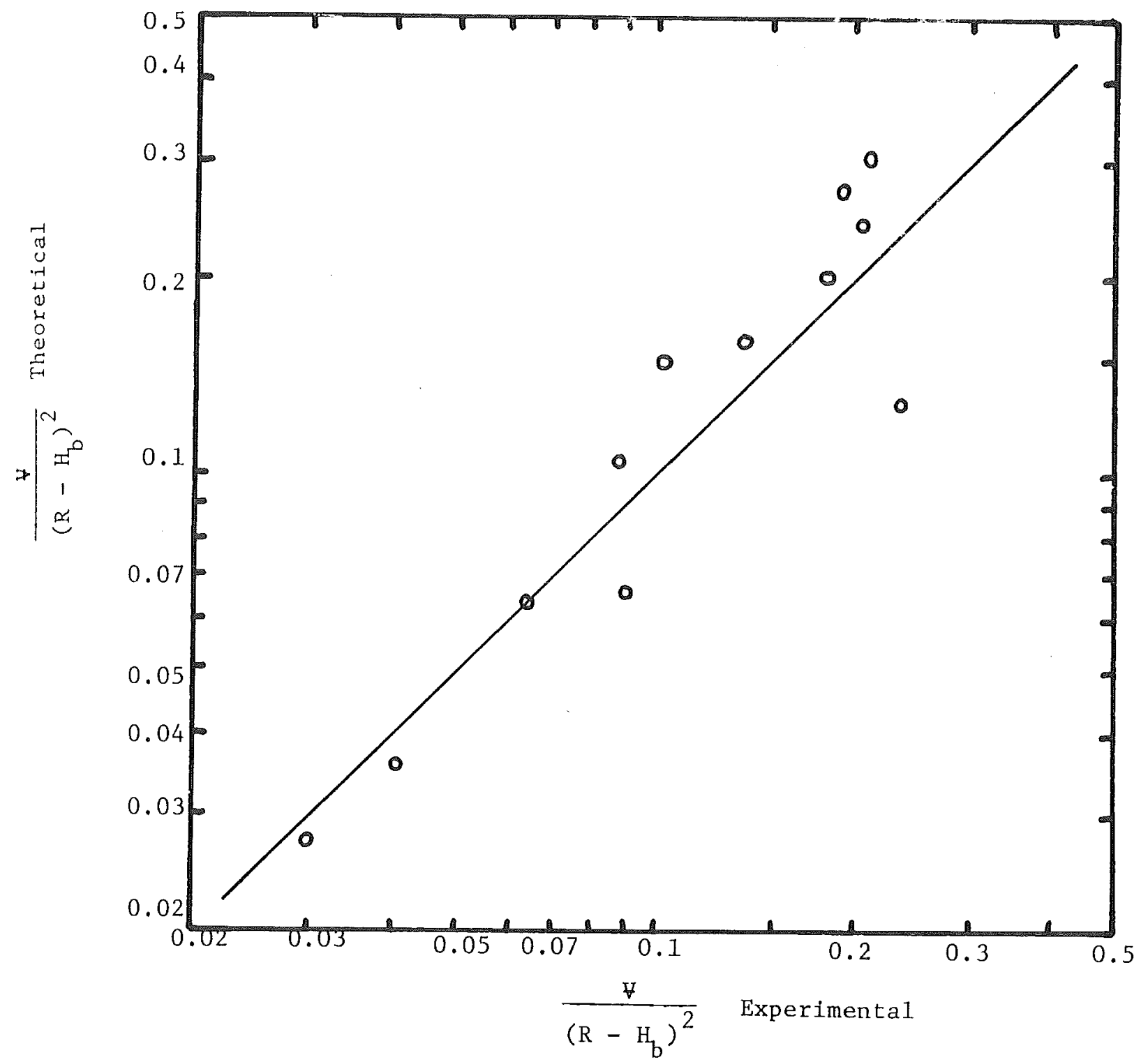

Figure 13 Comparison of Theoretical Overtopping Volumes with Saville's Data 


\section{LIST OF SYMBOLS}

A

A

${ }^{A} r$

$A_{i}$

C

$\mathrm{C}_{\mathrm{g}}$

E

$\mathrm{E}_{\mathbf{i}}$

E

e

$\mathrm{E}_{\mathbf{r}}$

$\mathrm{E}_{t}$

$\mathrm{H}$

$\mathrm{h}$

$\mathrm{H}_{\mathrm{b}}$

$h_{b}$

$\mathrm{H}_{\mathrm{i}}$

$k_{\ell}$

k

$k_{r}$

$\mathrm{k}_{\text {上 }}$

L

$\mathrm{L}_{\mathrm{R}}$ partial standing wave amplitude

incident wave amplitude

reflected wave amplitude

transmitted wave amplitude

wave celerity

energy propagation rate (group velocity)

run down energy

incident wave energy density

overtopping energy

dimensionless overtopping energy

reflected wave energy density

transmitted wave energy density

still water depth

dimensionless still water depth

breakwater crest elevation above SWL

dimensionless breakwater crest elevation

incident wave height

rundown loss coefficient

Miche's reflection coefficient

breakwater reflection coefficient

transmission coefficient

incident, reflected wave length

horizontal distance from first trough to point of maximum runup 
LIST OF SYMBOLS

(continued)

$\mathrm{L}_{\mathrm{t}}$

M

n

PE

pe

R

r

S

$s$

$\mathrm{T}$

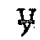

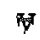

$\mathrm{X}$

$x_{1}, x_{2}$

$\mathrm{x}, \mathrm{x}_{1}, \mathrm{x}_{2}$

$\mathrm{Y}$

y

$\gamma$

$\rho$ transmitted wave length

constant coefficient in parabola equation

exponent in parabola equation

potential energy of runup wedge

dimensionless potential energy of runup wedge

runup height

dimensionless runup height

breakwater slope, seaward face

"dimensionless" breakwater slope, $S A / L_{R}$

wave period

overtopping volume

dimensionless overtopping volume

horizonta1 coordinate

horizontal distance to $Y=0, H_{b}$, respectively

dimensionless, $\mathrm{x}, \mathrm{x}_{1}, \mathrm{x}_{2}$

vertical coordinate

dimensionless vertical coordinate

specific weight

Miche's intrinsic reflection coefficient 